Subscriber access provided by Library, Special Collections and Museums, University of Aberdeen

\title{
Article
}

\section{Adsorbed Formate is the Last Common Intermediate in the Dual-Path Mechanism of the Electrooxidation of Formic Acid}

Alexander Betts, Valentin Briega-Martos, Angel Cuesta, and Enrique Herrero

ACS Catal., Just Accepted Manuscript • DOI: 10.1021/acscatal.0c00791 • Publication Date (Web): 22 Jun 2020

Downloaded from pubs.acs.org on June 29, 2020

\section{Just Accepted}

"Just Accepted" manuscripts have been peer-reviewed and accepted for publication. They are posted online prior to technical editing, formatting for publication and author proofing. The American Chemical Society provides "Just Accepted" as a service to the research community to expedite the dissemination of scientific material as soon as possible after acceptance. "Just Accepted" manuscripts appear in full in PDF format accompanied by an HTML abstract. "Just Accepted" manuscripts have been fully peer reviewed, but should not be considered the official version of record. They are citable by the Digital Object Identifier (DOI®). "Just Accepted" is an optional service offered to authors. Therefore, the "Just Accepted" Web site may not include all articles that will be published in the journal. After a manuscript is technically edited and formatted, it will be removed from the "Just Accepted" Web site and published as an ASAP article. Note that technical editing may introduce minor changes to the manuscript text and/or graphics which could affect content, and all legal disclaimers and ethical guidelines that apply to the journal pertain. ACS cannot be held responsible for errors or consequences arising from the use of information contained in these "Just Accepted" manuscripts. 


\section{Adsorbed Formate is the Last Common Intermediate in the Dual-Path Mechanism of the Electrooxidation of Formic Acid}

Alexander Betts,,$^{\dagger}$ Valentín Briega-Martos, ${ }^{\ddagger}$ Angel Cuesta ${ }^{*}, \dagger$ and Enrique Herrero ${ }^{*}, \ddagger$

tDepartment of Chemistry, School of Natural and Computing Sciences, University of Aberdeen, AB24 3UE, Scotland, UK

‡Instituto de Electroquímica, Universidad de Alicante, Apdo. 99, E-03080, Alicante, Spain

*Email: angel.cuestaciscar@abdn.ac.uk; herrero@ua.es

KEYWORDS. Formic acid; electrocatalysis; Pt(100); Pt(111); adsorbed formate. 
ABSTRACT. We report a study using $\mathrm{Pt}(111)$ and $\mathrm{Pt}(100)$ electrodes of the role of adsorbed formate in both the direct and indirect pathways of the electrocatalytic oxidation of formic acid. Cyclic voltammetry at different concentrations of formic acid and different scan rates, as well as pulsed voltammetry, were used to obtain a deeper insight into the effect of formate coverage on the rate of the direct pathway. Pulsed voltammetry also provided information on the effect of the concentration of formic acid on the rate of formation of adsorbed $\mathrm{CO}$ on $\mathrm{Pt}(100)$. At low to medium coverage, increasing formate coverage increases the rate of its direct oxidation, suggesting that decreasing the distance between neighboring bidentate adsorbed formate favors its interconversion to and/or stabilizes monodentate formate (the reactive species). However, increasing the formate coverage beyond approximately $50 \%$ results in a decrease of the rate of the direct oxidation, probably because bidentate formate is too closely packed for its conversion to monodentate formate to be possible. Cyclic voltammetry at very high scan rates reveals the presence of an order-disorder phase transition within the bidentate formate adlayer on $\mathrm{Pt}(111)$ when the coverage approaches saturation. The dependence of the potential of maximum rate of 


\begin{abstract}
dehydration to adsorbed $\mathrm{CO}$, and of the rate at the maximum, on the concentration of formic acid is in good agreement with predictions made for a mechanism in which adsorbed $\mathrm{CO}$ is formed through the adsorption of formate followed by its reduction to adsorbed $\mathrm{CO}$, thus confirming that monodentate adsorbed formate is the last intermediate common to both the direct and indirect pathways.
\end{abstract}

\title{
1. INTRODUCTION
}

The electrocatalytic oxidation of formic acid on platinum electrodes is among the electrochemical reactions that has attracted most interest for a long time..$^{1-2}$ The main reasons for this long-standing interest are (i) the relative simplicity of the reaction (only two electrons and two protons need to be transferred for its complete oxidation to $\mathrm{CO}_{2}$ ) and (ii) the possibility of using formic acid as a liquid fuel in fuel cells. Moreover, the knowledge gained in the study of this oxidation reaction can be transferred to those of other, more complex, organic molecules. 
The formation of a catalytic poison during the oxidation of formic acid on platinum was proposed as early as 1928 based on the oscillatory behavior of the reaction ${ }^{3}$ (92 years later, the formic acid oxidation reaction remains the archetype electrochemical oscillator), but Capon and Parsons ${ }^{4}$ were the first to propose that the reaction must proceed through two possible parallel pathways, one leading directly to the formation of $\mathrm{CO}_{2}$ without breaking any of the $\mathrm{C}-\mathrm{O}$ bonds (the so-called direct path) and a second one in which an adsorbed species that acts as a catalytic poison is formed and then oxidized to $\mathrm{CO}_{2}$ (the so-called indirect path). The actual adsorbate responsible for the poisoning of the Pt surface was the subject of intense debate for some time, until in situ infrared reflection absorption spectroscopy (IRRAS) provided unambiguous proof that the catalytic poison is adsorbed carbon monoxide ${ }^{5}$ (i.e., the indirect path involves the dehydration of formic acid to yield adsorbed $\mathrm{CO}$, which must then be oxidized to $\mathrm{CO}_{2}$ to complete the reaction).

Identification of the species mediating the direct path and the formation of adsorbed $\mathrm{CO}$ took much longer. In 2002 Miki et al. ${ }^{6}$ detected for the first time, using surface-enhanced 
infrared absorption spectroscopy in the attenuated total reflection configuration (ATR-

SEIRAS), the presence of bidentate adsorbed formate on the surface of a Pt electrode during the oxidation of formic acid, and proposed it to be the intermediate in the direct pathway. Later, based on the very good correlation between the rate of formation of adsorbed $\mathrm{CO}$ and the coverage by adsorbed bidentate formate as determined by ATRSEIRAS, Cuesta et al. ${ }^{7-8}$ suggested that this species is also the intermediate in the dehydration of formic acid (in other words, that this species corresponds to the point where the reaction separates into two pathways).

The correlation between the reaction rate and the coverage by this species seemed to support these claims, but work by others suggested that bidentate adsorbed formate is too stable to be the reactive intermediate ${ }^{9-10}$ and the activation energy for breaking the $\mathrm{C}-\mathrm{H}$ bond in this species is far too high ${ }^{11}$ for it to be the intermediate in any of the two paths. Chen et al. performed ATR-SEIRAS experiments coupled with a thin-layer electrochemical flow cell and proposed that formate would be a spectator species in a so-called "three pathway mechanism" in which the active intermediate would be 
different from adsorbed formate. ${ }^{12-13}$ This was supported by further experiments by Okamoto et al. ${ }^{14}$ and DFT calculations by Neurock et al., who suggested that adsorbed formate is relatively stable and proposed that a carboxylic acid species adsorbed through the carbon atom $(-\mathrm{COOH})$ would be the active species. ${ }^{15}$ More recently, Chen et al. suggested, based on modeling of galvanostatic potential oscillations, that the reactive intermediate in the direct pathway would be an unspecified anionic species. ${ }^{16}$ However, neither $-\mathrm{COOH}$ nor other intermediate species different from formate have been experimentally detected, and the dependence of the reaction rate on the $\mathrm{pH}$ of the electrolyte has unambiguously demonstrated that formate is the reactive intermediate. Since formate can adsorb in either monodentate or bidentate configuration, it has been proposed that the former is the actual reaction intermediate. ${ }^{17-21}$ Bidentate formate is nonetheless not a dead end, as it can still affect the reactivity by being in equilibrium with the reactive intermediate and/or contributing to stabilizing the reactive intermediate in its neighborhood ${ }^{21-22}$. Monodentate adsorbed formate has also been suggested to be the intermediate leading to adsorbed $\mathrm{CO}^{23-24}$ i.e., to play the role of the last common intermediate in the dual path initially assigned ${ }^{7-8}$ to bidentate formate. 
We report here a detailed study using $\mathrm{Pt}(111)$ and $\mathrm{Pt}(100)$ electrodes, cyclic

voltammetry and pulsed voltammetry that provides further insight into the roles of both

forms of adsorbed formate in the formic acid oxidation reaction. We show that

adsorption of formate is necessary for both pathways to proceed and that only at high

coverage does bidentate formate become a blocking species. Our results regarding the dependence of the potential at which the rate of dehydration is maximum and of the rate of dehydration at that maximum on the concentration of formic acid are in good agreement with previous predictions ${ }^{8}$ based on a mechanism for the indirect path in which the adsorption of formate is followed by its reduction to adsorbed CO.

\section{EXPERIMENTAL SECTION}

The platinum single-crystal electrodes, namely $\mathrm{Pt}(111)$ and $\mathrm{Pt}(100)$, were prepared

from small Pt beads ca. $2 \mathrm{~mm}$ in diameter, following the method described by Clavilier et al. ${ }^{25}$ Before every measurement, the electrode was flame annealed, cooled in an $\mathrm{Ar} / \mathrm{H}_{2}$ (3:1) atmosphere and protected with an ultrapure water drop saturated with these gases. They were then transferred to the glass electrochemical cell. This preparation 
procedure assures that the obtained experimental surfaces correspond to the nominal topographies. ${ }^{26}$ All measurements have been conducted using a Pt counter electrode and a reversible hydrogen electrode (RHE) as reference.

The solutions were prepared using $60 \% \mathrm{HClO}_{4}$ (Merck, for analysis), $\mathrm{HCOOH}$ (Merck, for analysis), $\mathrm{H}_{2} \mathrm{SO}_{4}$ (Merck, suprapur) and ultrapure water (Elga PureLab Ultra, 18.2 $\mathrm{M} \Omega \mathrm{cm}$ ). Electrochemical measurements were carried out by using a signal generator EG\&G PARC and eDAQ EA161 potentiostat with an Edaq e-corder ED401 recording system. Experiments in hydrodynamic conditions were performed with the hangingmeniscus rotating disk electrode (HMRDE) configuration using an EDI101 rotating electrode and a Radiometer CTV 101 for controlling the rotation rate (both from Radiometer Analytical). All experiments were carried out at room temperature.

\section{RESULTS AND DISCUSSION}

3.1. Adsorbed formate in the direct path. Although qualitatively $\mathrm{Pt}(111)$ and $\mathrm{Pt}(100)$ electrodes behave similarly for the formic acid oxidation reaction, there are significant 
differences in the dependence of the measured currents on the applied potential and the concentration of formic acid. These differences are evident even when simply comparing the voltammetric profiles the $\mathrm{Pt}(111)$ and $\mathrm{Pt}(100)$ electrodes in the presence of formic acid. Figure $1 \mathrm{~A}$ shows a typical cyclic voltammogram (CV) of $\mathrm{Pt}(111)$ in the presence of $0.05 \mathrm{M} \mathrm{HCOOH}$. It is important to highlight that the profiles do not change with successive cycling for all the electrodes used in this study, indicating the absence of possible contaminants and the stability of the surfaces in the potential window employed. For the $\mathrm{Pt}(111)$ electrode, currents in the positive and negative scan directions are almost identical, which indicates that the formation and accumulation of $\mathrm{CO}$ on the surface at low potentials is negligible. In fact, it has been shown that on $\mathrm{Pt}(111)$ electrodes the formation of $\mathrm{CO}$ only takes place at measurable rates on defect sites. $^{27}$

The $\mathrm{Pt}(100)$ electrode is significantly more active for the oxidation of formic acid through the direct path than the $\operatorname{Pt}(111)$ surface, as revealed by the considerably higher current densities achieved in the negative scan direction (Figure 1B). Moreover, the 
$\mathrm{Pt}(100)$ surface is also very active for the formation of adsorbed $\mathrm{CO}$ at low potentials, ${ }^{28}$ as revealed by the negligible oxidation currents recorded in the positive scan direction. At potentials below $0.4 \mathrm{~V}, \mathrm{Pt}(100)$ is a more active catalyst than $\mathrm{Pt}(111)$ for the dehydration of formic acid to adsorbed $\mathrm{CO}$, resulting in poisoning of the catalyst and a very low activity for the dehydrogenation of formic acid to $\mathrm{CO}_{2}$ in the positive-going scan. ${ }^{27}$ It should be noted that the actual currents measured in the first scan depend strongly on the time required to form the hanging meniscus and start the CV. Slightly higher currents can be measured when the meniscus is formed and the scan started rapidly. Above $0.8 \mathrm{~V}$, oxidative stripping of adsorbed CO reactivates the surface for the oxidation of formic acid. In the negative scan direction, high currents are measured which are associated with the oxidation of formic acid through the active intermediate. Below $0.5 \mathrm{~V}$, the current diminishes due to the combination of three different factors: (i) the lower overpotential, (ii) the less favorable adsorption of formate in both bidentate and monodentate configurations (see below) and (iii) CO poisoning. ${ }^{28}$ 


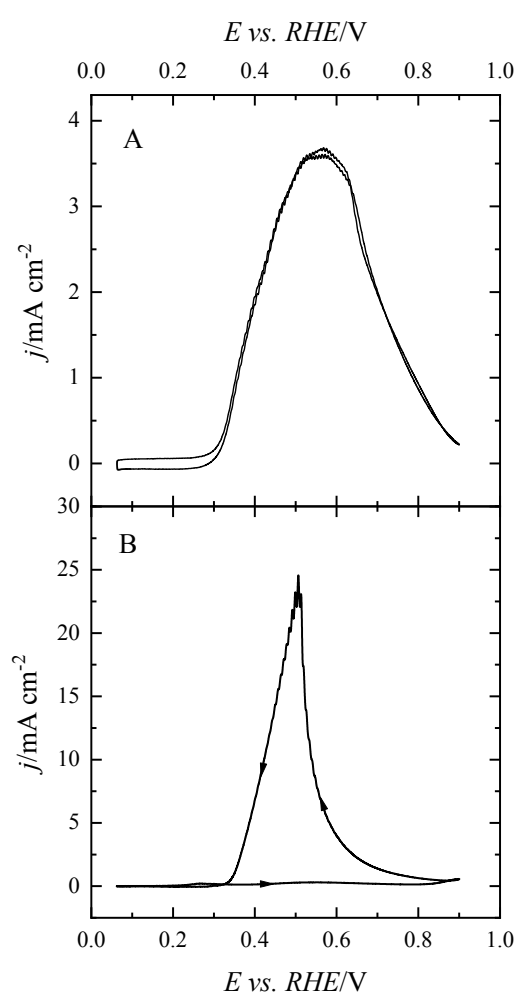

Figure 1. Voltammetric profiles at $0.05 \mathrm{~V} \mathrm{~s}^{-1}$ and $1600 \mathrm{rpm}$ in $0.1 \mathrm{M} \mathrm{HClO}_{4}+0.05 \mathrm{M}$ $\mathrm{HCOOH}$ of the $\mathrm{Pt}(111)(\mathrm{A})$ and $\mathrm{Pt}(100)(\mathrm{B})$ electrodes in a HMRDE configuration.

These voltammetric profiles must be analyzed in view of the mechanism of the reaction, for which it is generally accepted that the active intermediate is monodentate adsorbed formate. ${ }^{17-21}$ As aforementioned, formate can also be adsorbed in a bidentate configuration, ${ }^{6-8}$ which is the most stable form but also very unreactive. ${ }^{9-11}$ Adsorbed formate in the monodentate form can evolve either to the formation of $\mathrm{CO}_{2}$ or to the bidentate form. The latter, which would deactivate the species, is inhibited by the 


\begin{abstract}
presence of other neighboring adsorbed species, including other specifically adsorbing
anions and bidentate formate itself. ${ }^{21-22}$ Thus, the electrocatalytic oxidation of formic

acid requires the adsorption of formate in the monodentate form and its stabilization by

the presence of neighboring adsorbed molecules, such as formate in the bidentate

configuration, to prevent its transformation into the unreactive form. ${ }^{21}$
\end{abstract}

The increase and subsequent decrease of the current corresponding to the direct path

in the negative scan is sharper for $\mathrm{Pt}(100)$ than for $\mathrm{Pt}(111)$, which, according to the

proposed mechanism, should be related to differences in the adsorption behavior of

formate on the two surfaces. The adsorption of formate, whether from formic acid

(Reaction (2)) or from formate at higher $\mathrm{pH}$ or after the dissociation of $\mathrm{HCOOH}$

(Reaction (3)), involves the transfer of one electron, and, as happens with the specific

adsorption of most, if not all, anions, is a very fast, equilibrium process

$$
\begin{array}{r}
\mathrm{HCOOH}+* \rightleftharpoons \mathrm{HCOO}_{\mathrm{ad}}+\mathrm{H}^{+}+e^{-} \\
\mathrm{HCOO}^{-}+* \rightleftharpoons \mathrm{HCOO}_{\mathrm{ad}}+e^{-}
\end{array}
$$


Recently accumulated evidence regarding the dependence of the rate of oxidation of

formic acid on the electrolyte $\mathrm{pH}^{18-20}$ suggests that $\mathrm{HCOO}^{-}$, and not $\mathrm{HCOOH}$, is the active species, i.e., that dissociation of $\mathrm{HCOOH}\left(\mathrm{HCOOH} \rightleftharpoons \mathrm{HCOO}^{-}+\mathrm{H}^{+}\right)$precedes the formation of adsorbed formate, which is therefore better described by Reaction (3).

The current due to the adsorption of formate has, therefore, a pseudocapacitive nature, and will scale linearly with the scan rate. On the contrary, the current for the overall direct oxidation process scales with the square root of the scan rate, as it involves the diffusion of formic acid to the electrode surface. At very low scan rates, the current in the $\mathrm{CV}$ is overwhelmingly dominated by that corresponding to the overall faradaic process (see, e.g., CVs at $50 \mathrm{mV} \mathrm{s}^{-1}$ in Figure 1). However, if the scan rate increases, the pseudocapacitive current eventually becomes significantly higher than that due to the faradaic process and dominates the CV. An equivalent explanation is that, as the rate-determining step is the oxidation of monodentate adsorbed formate to $\mathrm{CO}_{2}$, the scan rate can eventually become too fast for this process to be observed, and the electroadsorption of formate is the only process contributing to the current in the $\mathrm{CV}$. 
In the case of the Pt(111) electrode, this strategy enables to observe and analyze the formate adsorption process. ${ }^{29}$ As can be seen in Figure $2 \mathrm{~A}$, as the scan rate increases, the shape of the CV evolves towards that typical of anion adsorption. In fact, the shape measured at $40 \mathrm{~V} \mathrm{~s}^{-1}$ resembles that obtained for acetic acid solutions for the same electrode. ${ }^{29}$ When the current is normalized by the scan rate, the CVs between 0.06 and 0.35 overlap at all scan rates, because this region correspond to the hydrogen adsorption process on the $\mathrm{Pt}(111)$ surface, also a pseudocapacitive process. On the other hand, the normalized current between 0.4 and $0.8 \mathrm{~V}$ decreases with increasing scan rate (Figure 2C) because it includes contributions from faradaic and pseudocapacitive processes. The normalized CVs for 20 and $40 \mathrm{~V} \mathrm{~s}^{-1}$ overlap, indicating that above $20 \mathrm{~V} \mathrm{~s}^{-1}$ the faradaic contribution to the voltammogram is negligible, and the current recorded between 0.4 and $0.8 \mathrm{~V}$ corresponds exclusively to the adsorption of formate. As can be seen when the CVs at low scan rates (Figure 2E) are compared with those at 20 or $40 \mathrm{~V} \mathrm{~s}^{-1}$ (Figs. $2 \mathrm{~A}$ and $\mathrm{C}$ ), the onset of the oxidation is seen to coincide with the onset of formate adsorption and the inhibition of the oxidation at high potentials occurs when the formate adlayer is just over $50 \%$ complete. 
Moreover, the small wave observed at high scan rates in the negative scan direction at ca. $0.6 \mathrm{~V}$, which is probably associated to changes in the formate adlayer, also has an effect in the oxidation current, as indicated by a sharp increase in the current at low scan rates at exactly the same potential. A similar effect has been observed during the oxidation of formic acid on $\mathrm{Au}(111)^{30}$ and was attributed to a disorder-order transition within the formate adlayer at high coverage, as confirmed recently by comparing the behavior of formate with that of unreactive acetate on $\mathrm{Au}(111)$ electrodes. ${ }^{31} \mathrm{As}$ far as we know this is the first report of this phase transition in the formate adlayer also taking place on Pt(111) electrodes, although this process can also be identified in the recentlyreported CVs of Pt(111) in very concentrated solutions of perchloric acid containing formic acid. ${ }^{32}$ 
Evs. RHE/V

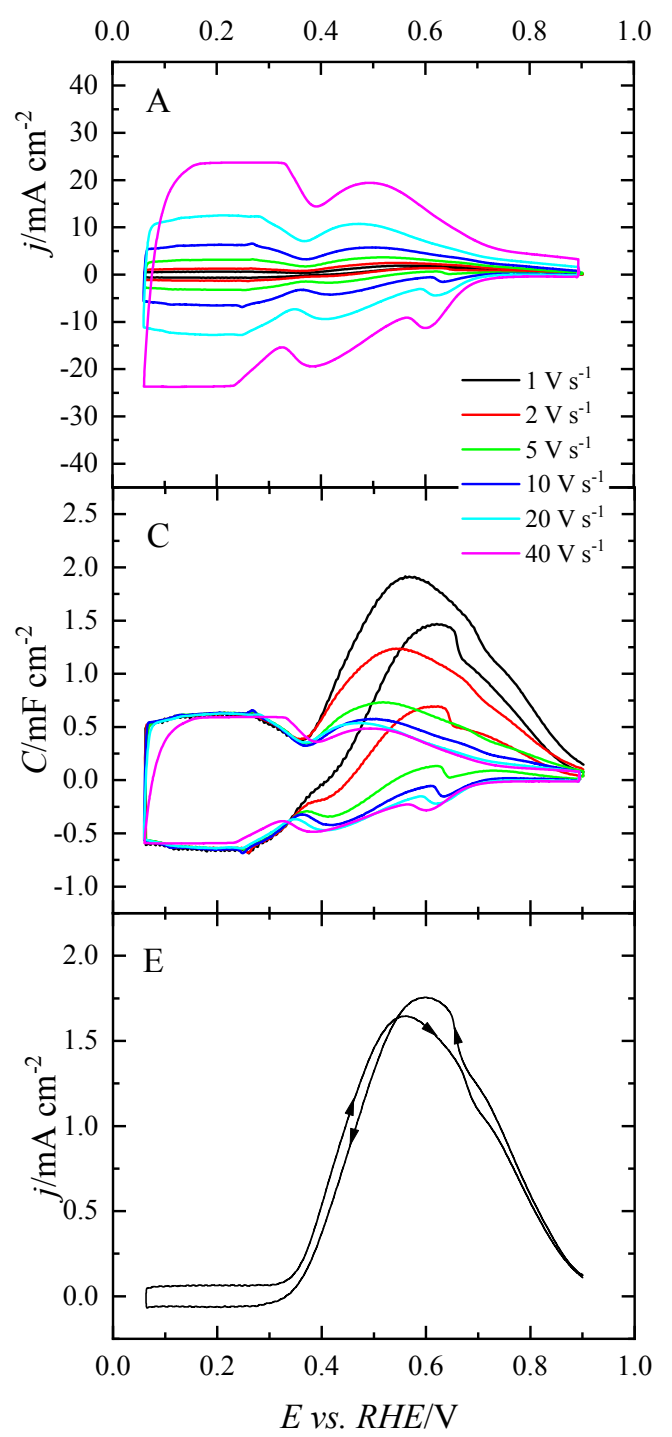

Evs. RHE/V

$\begin{array}{lllllllllll}0.0 & 0.1 & 0.2 & 0.3 & 0.4 & 0.5 & 0.6 & 0.7 & 0.8 & 0.9 & 1.0\end{array}$

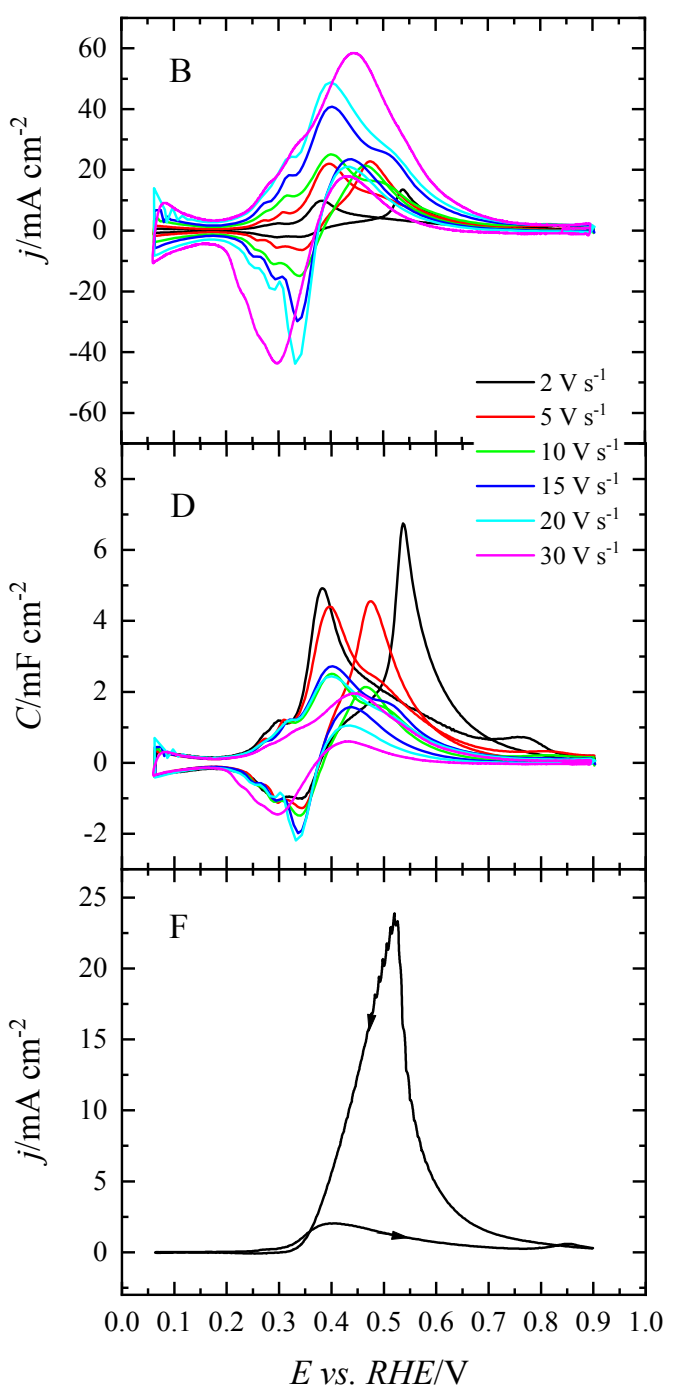

Figure 2. Scan rate dependence of the voltammetric profile of the $\operatorname{Pt}(111)$ (A) and

$\mathrm{Pt}(100)(\mathrm{B})$ electrodes in $\left.0.1 \mathrm{M} \mathrm{HClO}_{4}+0.01 \mathrm{M} \mathrm{HCOOH} . \mathrm{C}\right)$ and $\mathrm{D}$ ) are Capacitance

(i.e., current density normalized by scan rate) vs. potential plots of the $\mathrm{Pt}(111)$ and $\mathrm{Pt}(100)$ electrodes, respectively. E) and F) are the voltammetric profiles the $\mathrm{Pt}(111)$ and 
$\mathrm{Pt}(100)$ electrodes in $0.1 \mathrm{M} \mathrm{HClO}_{4}+0.01 \mathrm{M} \mathrm{HCOOH}$ electrode at $0.05 \mathrm{~V} \mathrm{~s}^{-1}$. IR drop has been corrected in all cases.

The same strategy can be used with $\mathrm{Pt}(100)$, although the high currents recorded for the direct oxidation may impede the observation of the adsorption process. As can be seen in Figure $2 B$ and $D$, the qualitative evolution of the voltammogram is the same as that of Pt(111), however, faradaic currents are still not negligible for $30 \mathrm{~V} \mathrm{~s}^{-1}$. For this scan rate, the voltammogram is already distorted due to the fraction of the total IR drop that cannot be compensated. In spite of that, the voltammetric profile of the $\mathrm{Pt}(100)$ electrode measured at $20 \mathrm{~V} \mathrm{~s}^{-1}$, especially in the negative scan direction, already resembles that measured for the same electrode in acetic acid solutions. ${ }^{33}$ In fact, a sharp peak at ca. $0.35 \mathrm{~V}$ is observed, which is equivalent to that observed in the same conditions in acetic acid solutions, and the shape of the voltammogram below that potential is essentially the same as that measured in acetic or sulfuric acid solutions. Above $0.4 \mathrm{~V}$, the faradaic currents are not negligible at $20 \mathrm{~V} \mathrm{~s}^{-1}$, distorting the expected shape. Thus, the adsorption behavior of formate on the $\mathrm{Pt}(100)$ surface is essentially 
the same as that observed in acetic acid/acetate solution. The peak at $0.35 \mathrm{~V}$, therefore, corresponds to the competitive adsorption processes of hydrogen and formate. At 0.06 $\mathrm{V}$, the surface is covered by an adsorbed hydrogen monolayer. The desorption of this layer starts at $0.2 \mathrm{~V}$. As hydrogen is desorbed, formate can adsorb on the surface in a competitive process, which gives rise to the sharp peak at $0.35 \mathrm{~V} .{ }^{33}$ Finally, the adsorption process of formate is completed at ca. $0.45 \mathrm{~V}$. Since at $0.85 \mathrm{~V}$ bidentate adsorbed formate forms a compact layer on $\mathrm{Pt}(100)$, currents are very low, as happens for the Pt(111) surface.

It is worth noting that the adsorption process of formate takes place on a much narrower potential window on $\mathrm{Pt}(100)$ than on $\mathrm{Pt}(111)$. On the $\mathrm{Pt}(100)$ electrode, it starts around 0.25-0.3 V, and it is completed at 0.45-0.5 V, whereas for the $\operatorname{Pt}(111)$ surface, the adsorption region spans between 0.3 and $0.7 \mathrm{~V}$. This difference in the adsorption behavior has its effect in the current corresponding to the direct oxidation of formic acid. On the $\mathrm{Pt}(100)$ surface, the process is faster leading to a sharp current increase in the region below $0.4 \mathrm{~V}$. Similarly, as the completion of the formate layer is 
attained at lower potentials, the decay above $0.5 \mathrm{~V}$ is also stepper. On the other hand, the formate adsorption process on $\mathrm{Pt}(111)$ occurs over a wider potential region, and the changes in the formic-acid oxidation current are therefore more gradual.

DFT calculations indicate that the adsorption energy of formate (in both configurations, bidentate and monodentate) on both surfaces is very similar and, therefore, the differences described above must be due to the competition between formate and hydrogen for the adsorption sites on $\mathrm{Pt}(100) .{ }^{21}$ In absence of adsorbed hydrogen, the onset of formate adsorption on $\mathrm{Pt}(100)$ should have occurred around its potential of zero free charge (pzfc). The experimental value of the pzfc of $\mathrm{Pt}(100)$ is not available. However, it can be estimated from that of the Pt(111) electrode $(0.34 \mathrm{~V})^{34-35}$ and the difference between the work functions of $\mathrm{Pt}(100)$ and $\mathrm{Pt}(111)(\mathrm{ca} .0 .1 \mathrm{eV}){ }^{36}$ Thus, the onset for adsorption, in absence of adsorbed hydrogen, would have occurred around $0.25 \mathrm{~V}$, and probably the region where formate coverage changes are recorded would have also spanned ca. $0.4 \mathrm{~V}$, as with $\mathrm{Pt}(111)$ (on which surface formate adsorption indeed starts around the pzfc when, coincidentally, desorption of hydrogen is 
nearly complete). However, due to the presence of adsorbed hydrogen, adsorption of

formate on $\mathrm{Pt}(100)$ only occurs once some hydrogen has been already desorbed. As

soon as hydrogen is displaced from the surface, the formate coverage should reach its

equilibrium values, and a fast change in coverage is observed. Thus, the number of

formate species adsorbing on the surface as the potential changes is higher on the

Pt(100) surface, which implies a higher possibility of adsorbing in the monodentate

configuration and higher currents.

Figure $3 \mathrm{~A}$ shows $\mathrm{CVs}$ of a $\mathrm{Pt}(111)$ electrode in $0.1 \mathrm{M} \mathrm{HClO}_{4}$ with different formic acid concentrations (the same data with the complete set of studied concentrations is shown in Figure S1A). In all cases, a HMRDE configuration has been used to avoid problems arising from transport limitations when low formic acid concentrations are used. For clarity, only the negative scan direction is shown. The observed behavior agrees with the proposed mechanism. As expected, the onset shifts to lower potential values and higher currents are measured as the formic acid concentration increases from 0.005 to $2 \mathrm{M}$. However, the increase in current is lower than expected: a three orders of 


\begin{abstract}
magnitude increase in the concentration (from 0.001 to $1 \mathrm{M}$ ) leads to just a roughly 3 -
fold increase in the currents at the maximum (from 1.9 to $6 \mathrm{~mA} \mathrm{~cm}^{-2}$ ), clearly indicating the presence of a limitation in the kinetics of the reaction.
\end{abstract}




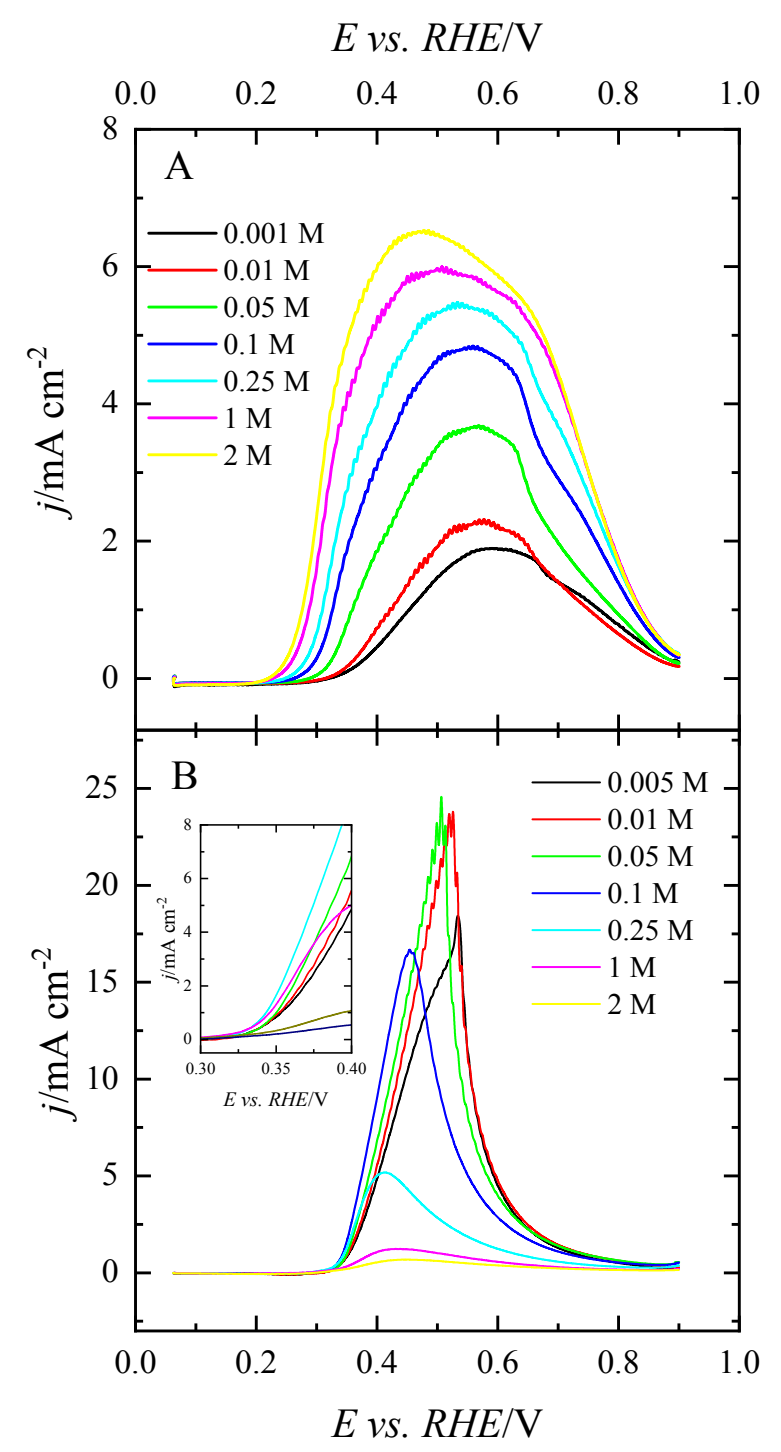

Figure 3. Evolution of the voltammetric profile of the $\operatorname{Pt}(111)(A)$ and $\operatorname{Pt}(100)$ (B) electrodes in a HMRD configuration with increasing formic acid concentration in $0.1 \mathrm{M}$ $\mathrm{HClO}_{4}$. Scan rate: $50 \mathrm{mV} \mathrm{s}{ }^{-1}$; rotation rate: $1600 \mathrm{rpm}$.

Figure 3B (and S1B) shows the evolution of the CV of a $\mathrm{Pt}(100)$ electrode as the formic acid concentration increases from $0.005 \mathrm{M}$ to $2 \mathrm{M}(0.005 \mathrm{M}$ formic acid was 
chosen as lower concentration because, below this value, a significant part of the voltammograms already shows a diffusion-controlled behavior). The effects of increasing the concentration of formic acid on the voltammogram differ from those observed with $\mathrm{Pt}(111)$ electrodes (Figure $3 \mathrm{~A}$ ), showing a more complex behavior. In the region between 0.85 and $0.5 \mathrm{~V}$, the oxidation onset and the current maximum shift to lower potential values as the concentration increases, as expected if the current in this region is related to the creation of free sites in the bidentate formate adlayer to allow for the adsorption of the active intermediate (as the concentration increases, the desorption in the negative scan direction starts at more negative potential values). On the other hand, currents at potentials below $0.5 \mathrm{~V}$ follow a different trend: (i) peak currents are constant between 0.01 and $0.05 \mathrm{M}$ and then decrease as the concentration increases; (ii) the currents between 0.4 and $0.3 \mathrm{~V}$ first increase with increasing concentration between 0.005 and $0.25 \mathrm{M}$, but decrease above $0.25 \mathrm{M}$ (inset in Figure 3B). This behavior clearly reveals some important kinetic limitation for the reaction as well as the effects of $\mathrm{CO}$ poisoning on the voltammogram, because the rate of formation of adsorbed $\mathrm{CO}$ also increases with increasing concentration (see below), affecting the 
final shape of the voltammogram. This latter effect is not observed on the Pt(111)

surface, because the rate of the $\mathrm{CO}$ poisoning is negligible for all the studied

concentrations (positive and negative scan directions of the voltammetric profile almost

overlap completely for all concentrations, as shown, e.g., in Figure $1 \mathrm{~A}$ and $2 \mathrm{E}$ for the

particular cases of $0.05 \mathrm{M}$ and $0.01 \mathrm{M} \mathrm{HCOOH}$, respectively).

In order to properly analyze these differences in the behavior of $\mathrm{Pt}(111)$ and $\mathrm{Pt}(100)$,

the rate of the direct path needs to be measured. For the $\mathrm{Pt}(111)$ electrode, during the voltammetric scan at $50 \mathrm{mV} \mathrm{s}^{-1}$, the formation of $\mathrm{CO}$ through the dehydration reaction of formic acid is negligible, and thus, the measured currents correspond to the direct oxidation path. On the other hand, on the $\mathrm{Pt}(100)$ surface, $\mathrm{CO}$ formation rate is significant, especially below $0.5 \mathrm{~V} .{ }^{28}$ Thus, the measured currents in the voltammogram correspond to a surface which is partially blocked by CO. In order to obtain the true activity of a free surface, pulsed experiments were performed. ${ }^{28,37}$ During the conditioning pulse at potentials above $0.8 \mathrm{~V}, \mathrm{CO}$ is fully oxidized. After 1 second at this potential, the potential is stepped to the desired potential, and the oxidation current 
transient is recorded (Figure 4). The decay in the transient reflects the progressive increase of the $\mathrm{CO}$ coverage, whereas the initial current at $\mathrm{t}=0$ would be the current measured in the absence of $\mathrm{CO}$. Since this value is not directly measurable, because of double layer charging at short times, a kinetic model for the reaction needs to be used to fit the transients. ${ }^{28}$ The kinetic model employed here is the same one used previously, ${ }^{28}$ in which the current measured for the oxidation of formic acid in the potential region where adsorbed $\mathrm{CO}$ cannot be oxidized is directly proportional to the fraction of the surface not covered by $\mathrm{CO}$ :

$$
j=j_{\theta=0}\left(1-\theta_{\mathrm{CO}}\right)
$$

where $j_{\theta=0}$ is the current at $t=0$ when $\theta_{\mathrm{CO}}=0$ (with $\theta_{\mathrm{CO}}$ the relative coverage by CO).

The overall reaction for the formation of adsorbed $\mathrm{CO}$ can be described as:

$$
\mathrm{HCOOH}+p * \rightarrow \mathrm{CO}_{\mathrm{ad}}+\mathrm{H}_{2} \mathrm{O}
$$

where $p$ corresponds to the number of free Pt sites required. The rate of formation of $\mathrm{CO}_{\mathrm{ad}}$ will therefore be given by:

$$
\frac{d \theta_{\mathrm{CO}}}{d t}=k_{\mathrm{ads}}\left(1-\theta_{\mathrm{CO}}\right)^{p}
$$


where $k_{\text {ads }}$ is the apparent rate constant for the dehydration reaction (see below for a discussion of the mechanism of the dehydration reaction and the meaning of $k_{\text {ads }}$ ). Integration of Eq (6) leads to the following expression for $\theta_{\mathrm{CO}}$ :

$$
\theta_{\mathrm{C} O}=1-\left(\frac{1}{1+k_{\text {ads }} t(p-1)}\right)^{\frac{1}{p-1}}
$$

for $p \neq 1$. For $p=1$, an exponential decay is obtained, ${ }^{27}$ but as will be shown below, this is not the case for the present experimental results. The substitution of Eq. (6) into Eq.

(4) yields:

$$
j=j_{\theta=0}\left(\frac{1}{1+k_{\text {ads }} t(p-1)}\right)^{\frac{1}{p-1}}
$$

Eq. (8) is able to reproduce the experimental results at $E<0.6 \mathrm{~V}$, and allows obtaining $j_{t=0}$ and $k_{\text {ads }}$, the best fittings corresponding to values of $p$ around 2 (as we will see below, this is in excellent agreement with the experimental determination of the minimum atomic ensemble required for the dehydration of $\mathrm{HCOOH}$ on $\mathrm{Pt}^{38-39}$ ). At $E>$ $0.6 \mathrm{~V}$ the current transients are constant because no formation of adsorbed CO takes place. Accordingly, the current measured in the transient is a direct measure of the rate of $\mathrm{CO}_{2}$ formation along the direct path. 


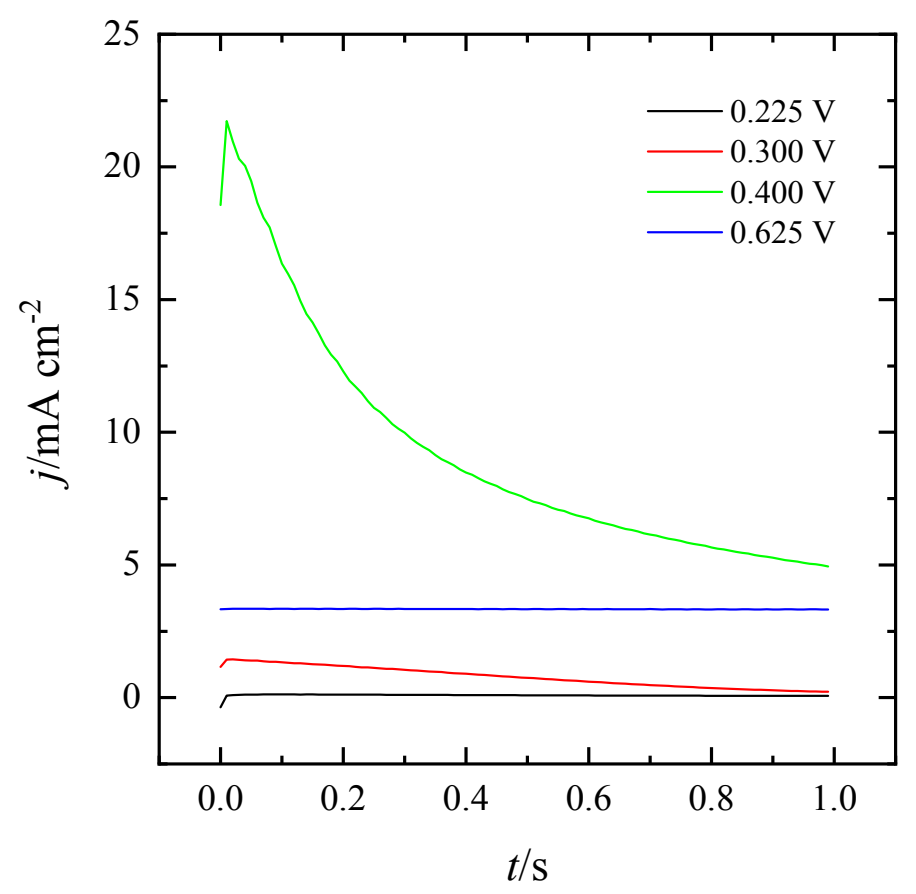

Figure 4. Transients measured for the pulsed voltammetry at different potentials for the $\mathrm{Pt}(100)$ electrode in $0.1 \mathrm{M} \mathrm{HClO}_{4}+0.01 \mathrm{M} \mathrm{HCOOH}$.

Figure 5 shows the values of $j_{t=0}$ on the $\operatorname{Pt}(100)$ electrode for different concentrations of formic acid (Figure S2 shows the same data for all the studied concentrations). For the lowest concentration $(0.005 \mathrm{M})$, the magnitude of $j_{t=0}$ is nearly constant between 0.42 and $0.57 \mathrm{~V}$, a clear indication that in this region and for this concentration, the rate of the reaction is limited by the diffusion of formic acid molecules to the surface. On the other hand, for the range of concentrations between 0.1 and $0.01 \mathrm{M}$, the values of $j_{t=0}$ around the maximum are nearly independent of the concentration, within the error of the 
measurements. In this range of concentrations, the only significant change is the slight displacement of the onset to lower potential values. It should be noted that the onset of the reaction coincides with that of formate adsorption on this electrode, as described above, which expectedly shifts negatively with increasing concentration of formic acid. For the higher concentrations, the current decreases with increasing concentration.

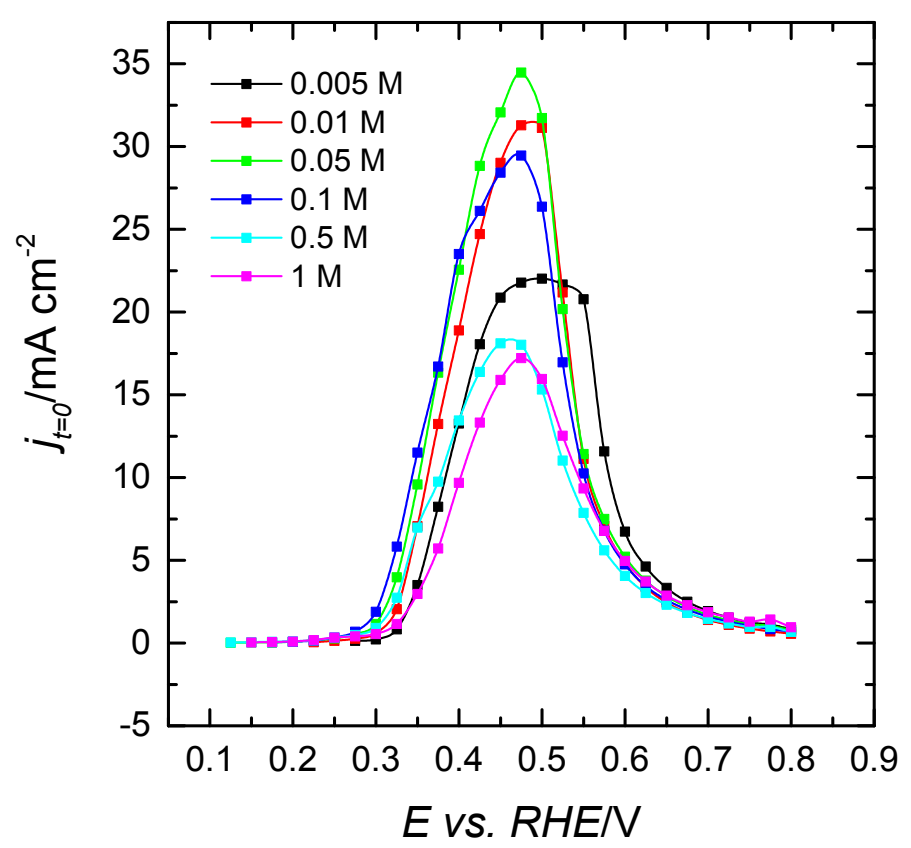

Figure 5. Values of $j_{t=0}$ for the different formic acid concentrations in $0.1 \mathrm{M} \mathrm{HClO}_{4}$ obtained after the analysis of the transients obtained with the pulsed voltammetry on the $\operatorname{Pt}(100)$ electrode. 
The almost identical values of $j_{t=0}$ around the maximum for $[\mathrm{HCOOH}]<0.1 \mathrm{M}$ suggest that the reaction rate for the $\mathrm{Pt}(100)$ electrode in this potential region is almost independent of the concentration of formic acid in solution. As in any heterogeneous catalyzed reaction, the formation of the active intermediate requires a solution species, formate in this case, and a surface site. The independence of the rate on the concentration implies that the surface site is the limiting reactant for the kinetics. The activity at a given potential must then be controlled by the residence time of the active intermediate on the surface, that is, the turnover rate of the site. Thus, all the available sites for the reaction are occupied by the active intermediate, provided that diffusion suffices to maintain its coverage, that is for $[\mathrm{HOOH}]>0.005 \mathrm{M}$. The time elapsed between adsorption of formate and its transformation to $\mathrm{CO}_{2}$, will determine the reaction rate at a given potential.

The behavior for the $\mathrm{Pt}(111)$ electrode is different, displaying a clear increase of the current with increasing concentration at all concentrations and at all potentials. In order to discard whether these difference is due to a different reaction mechanism, the reaction order for $\mathrm{HCOOH}$ was determined for both surfaces, by plotting either the 
current density in the $\mathrm{CV}$ at constant potential $\left(\mathrm{Pt}(111)\right.$ electrode) or $j_{t=0}$ at constant potential (Pt(100) surface) vs. the $\mathrm{HCOOH}$ concentration in a double logarithmic plot (Figure 6). The selected potentials were chosen close to the onset of the reaction because, in this region, the formate coverage is low and therefore the number of free sites is still large, and the reaction rate increases with potential for both $\mathrm{Pt}(100)$ and $\mathrm{Pt}(111)$. As can be seen in Figure 6, for $\mathrm{Pt}(100)$ a linear plot is observed for concentrations lower than $0.5 \mathrm{M}$. At higher concentrations, other effects are playing a role in the activity. The slopes of the double logarithmic plots in the linear region are ca. 0.6 at 0.300 and $0.325 \mathrm{~V}$. At $E=0.350 \mathrm{~V}$, the slope is lower because this potential is closer to the maximum current, and thus the reaction rate is controlled by the coverage of the adsorbed species. For Pt(111) a similar slope of ca. 0.66 is obtained in all cases. For this electrode and at $E=0.300 \mathrm{~V}$, the points at the lowest concentrations deviate from linearity because of the errors in measuring the very small currents registered at these concentrations. For $E=0.375 \mathrm{~V}$ and $[\mathrm{HCOOH}]>0.1 \mathrm{M}$, a deviation from linearity is observed because currents are reaching the peak values and they are no longer in the ascending branch of the voltammogram, but rather on the plateau region. The very 
identical values, within the error of the experiments, of the reaction order for $\mathrm{Pt}(111)$ and
$\mathrm{Pt}(100)$, imply that the mechanism is the same for both electrodes, i.e., the reaction rate is governed by the ability of the surface to form the active intermediate and the residence time of this adsorbed intermediate to yield $\mathrm{CO}_{2}$. 


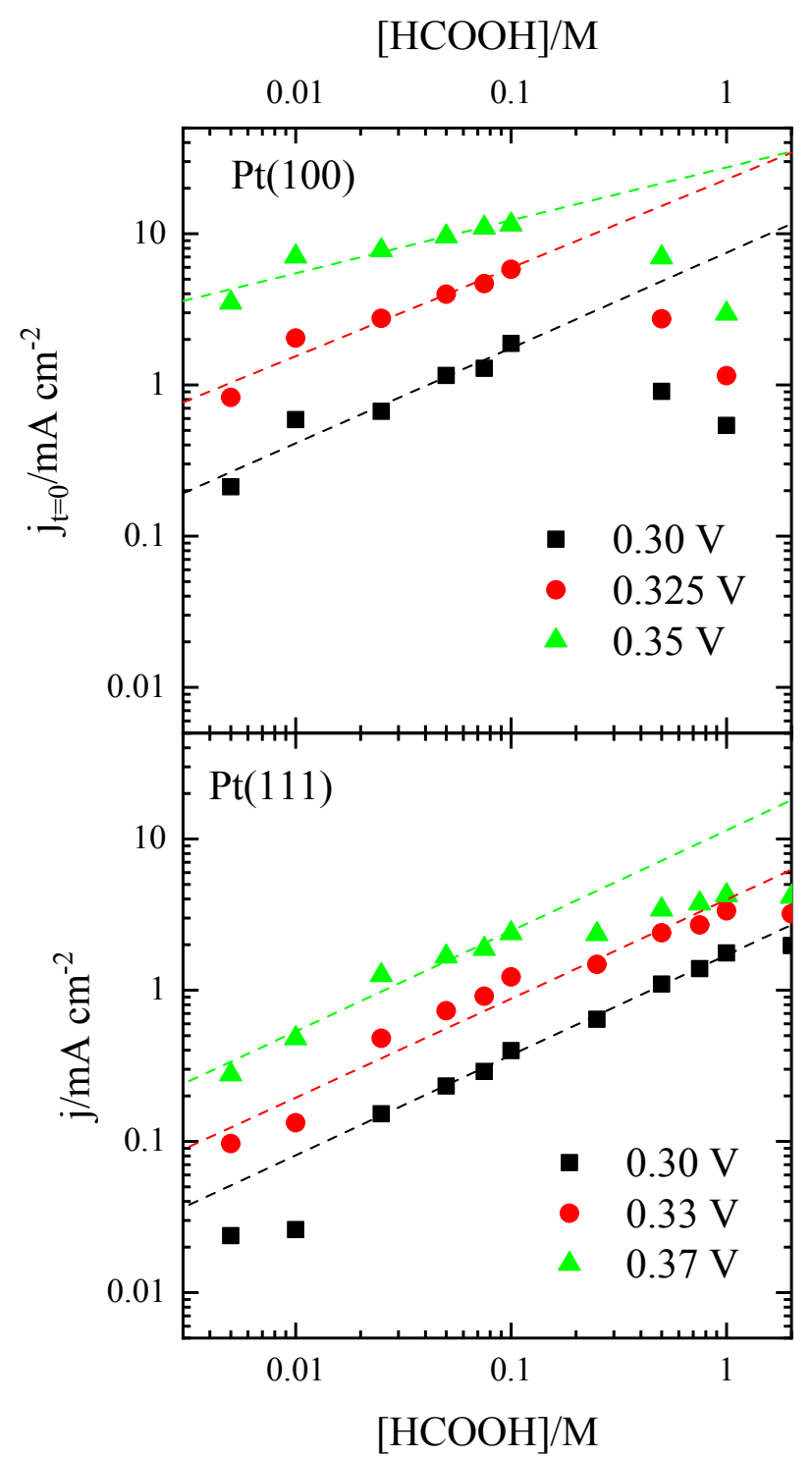

Figure 6. Double logarithmic plots of $j_{t=0}$ for $\operatorname{Pt}(100)$ and $j$ for $\operatorname{Pt}(111)$ electrodes at constant potential vs. the formic acid concentration in $0.1 \mathrm{M} \mathrm{HClO}_{4}$.

The effect of the specific adsorption of anions other than formate was examined by using a $0.1 \mathrm{M}$ sulfuric acid solution as supporting electrolyte. In this electrolyte, 
adsorbed sulfate is present on the surface in the potential region in which the formic acid oxidation reaction takes place. As can be seen in Figure 7 the qualitative behavior is the same as that measured in perchloric acid solutions (Figure 3): for Pt(111), the currents increase and the onset is displaced to more negative potentials as the concentration increases, whereas for $\mathrm{Pt}(100)$ surface, the current is almost independent of the concentration in the range between 0.01 and $0.1 \mathrm{M}$ and the onset also shifts to lower potentials with increasing concentration, but only up to $0.25 \mathrm{M}$. This implies that, in the presence of an adsorbed species that induces the positioning of formate in the right configuration, the current depends on the interaction of formate with the surface. In fact, as can be seen in Figures S3 and S4, where voltammograms for the same formic acid concentration in both electrolytes are compared, the onset of the reaction is slightly lower in sulfuric acid solutions. Moreover, currents for the Pt(100) electrode in sulfuric acid are higher than in perchloric, whereas for the $\mathrm{Pt}(111)$ surface, currents are similar except for the lowest concentration. All these results reinforce the idea that the driving force for the reaction is the nature of the interaction between formate and the surface, which is potential dependent. 

Evs. RHE/V

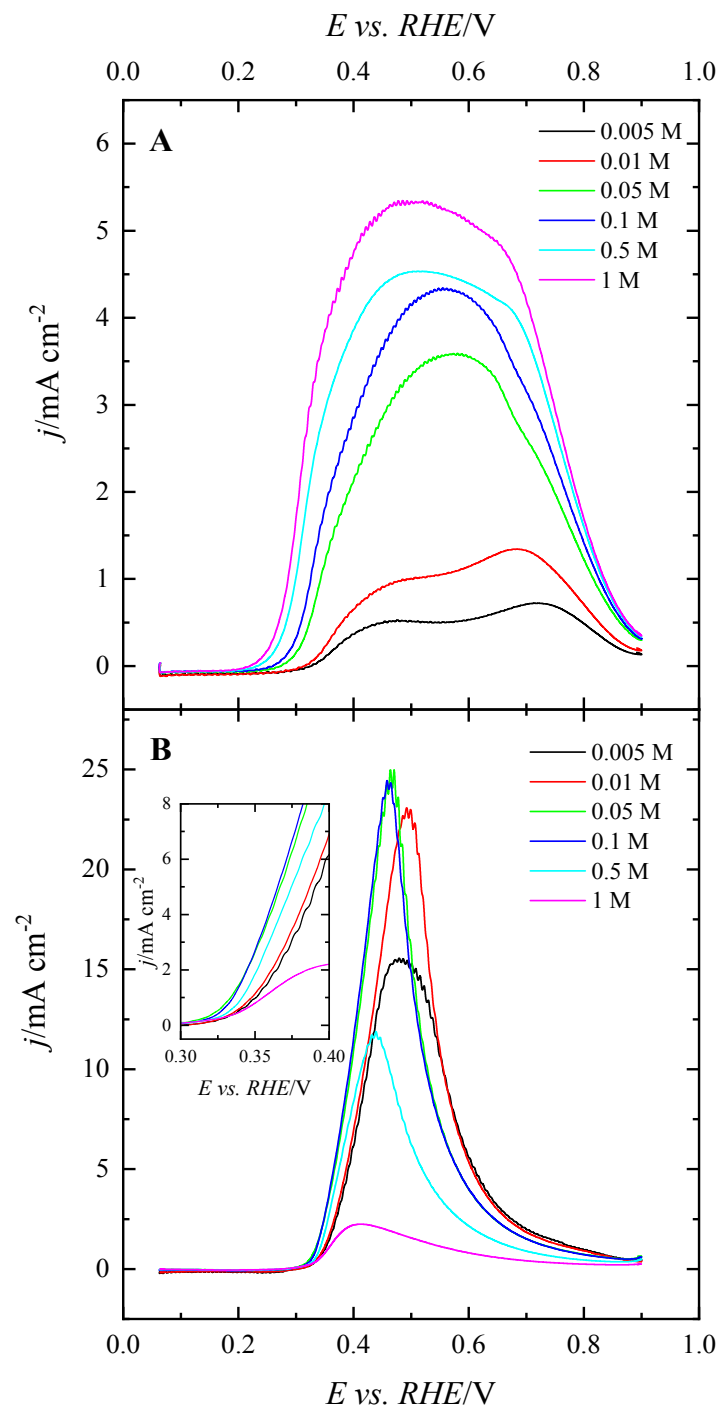

Figure 7. Evolution of the voltammetric profile of $\mathrm{Pt}(111)(\mathrm{A})$ and $\mathrm{Pt}(100)(\mathrm{B})$ in a HMRD configuration with increasing formic acid concentration in $0.1 \mathrm{M} \mathrm{H}_{2} \mathrm{SO}_{4}$. The inset shows an enlargement of the region between 0.3 and $0.4 \mathrm{~V}$. Only negative scan directions are shown for clarity. Scan rate: $50 \mathrm{mV} \mathrm{s}^{-1}$; rotation rate: $1600 \mathrm{rpm}$. 
3.2. Adsorbed formate in the indirect path. The dual-path mechanism of formic acid oxidation requires that there must be a last intermediate common to both paths. We will provide here additional evidence showing that, as has been previously suggested, ${ }^{23-24}$ adsorbed monodentate formate is this last common intermediate. According to this hypothesis, in the indirect path leading to adsorbed CO, Reaction 2 would be followed by the reduction of monodentate adsorbed formate:

$$
\mathrm{HCOO}_{\mathrm{ad}}+\mathrm{H}^{+}+e^{-} \rightarrow \mathrm{CO}_{\mathrm{ad}}+\mathrm{H}_{2} \mathrm{O}
$$

which would be the rate determining step in the Pt-catalyzed dehydration of formic acid.

The rate of formation of adsorbed $\mathrm{CO}$ would therefore be:

$$
\frac{d \theta_{\mathrm{CO}}}{d t}=k^{0} \exp \left(\frac{-(1-\beta) F \eta}{R T}\right) c_{\mathrm{H}}+\theta_{\text {formate }}\left(1-\theta_{\mathrm{CO}}\right)^{p}
$$

where $k^{\circ}$ and $\beta$ are the standard rate constant and the symmetry factor of Reaction 8 , respectively, $\eta$ is the overpotential (measured with respect to the standard potential of Reaction 8$), c_{\mathrm{H}^{+}}$is the proton concentration and $R$ and $T$ have their usual meaning. At constant $\mathrm{pH}$ and defining $k^{\#}=k^{\mathrm{o}} C_{\mathrm{H}^{+}}$Equation 9 is identical to Equation 5 , with $k_{\mathrm{ads}}=k^{\#}$ $\exp \left(\frac{-(1-\beta) F \eta}{R T}\right) \theta_{\text {formate }}$ 
As described above, in the case of $\mathrm{Pt}(100) k_{\mathrm{ads}}$ can easily be obtained from a fit of the current transients in Fig. 4 to Equation 7. The fact that the best fits are obtained for $p \approx$ 2, suggesting that two Pt free adsorption sites are required in addition to that occupied by adsorbed monodentate formate, is in excellent agreement with the well-established fact that a minimum atomic ensemble consisting of three contiguous $\mathrm{Pt}$ atoms is required for the dehydration of formic acid. $38-39$

Figure 8 shows a plot of $k_{\text {ads }}$ on $\mathrm{Pt}(100)$ as a function of the electrode potential. At the initial stages of the reaction, $\theta_{\mathrm{CO}}=0$, and, therefore, $\frac{d \theta_{\mathrm{co}}}{d t}=k^{\#} \exp \left(\frac{-\beta F \eta}{R T}\right) \theta_{\text {formate }}=k_{\mathrm{ads}}$, i.e., $k_{\text {ads }}$ corresponds to the rate of the dehydration reaction at $t=0$. The bell-shaped plots in Figure 6 are in agreement with previously reported results, ${ }^{27-28}$ as well as with the reaction mechanism proposed in refs ${ }^{7-8,23-24}$, in which monodentate adsorbed formate is the precursor of adsorbed $\mathrm{CO}$. The fact that no $\mathrm{CO}$ forms at all below $0.2 \mathrm{~V}$ is also consistent with this mechanism because, as has been shown above, at more negative potentials adsorption of formate is blocked by hydrogen adsorption. As discussed in ${ }^{8}$, for this mechanism, and assuming that the adsorption of formate can be 
described by a Langmuir isotherm, the potential at which the rate of dehydration is maximum $\left(E_{\max }\right)$ must shift negatively with increasing concentration of formic acid according to:

$$
E_{\max }=\left\{2.3 \frac{R T}{F}\left[\log \left(\frac{\beta}{1-\beta}\right)-\frac{1}{2} \log K_{\mathrm{L}}\right]+E_{\mathrm{pzc}}\right\}-2.3 \frac{R T}{F} \log c_{\mathrm{HCOOH}}
$$

where $K_{\mathrm{L}}$ is the Langmuir constant of the formate adsorption equilibrium, $E_{\mathrm{pzc}}$ is the potential of zero charge and $\mathrm{CHCOOH}_{\mathrm{H}}$ is the concentration of formic acid.

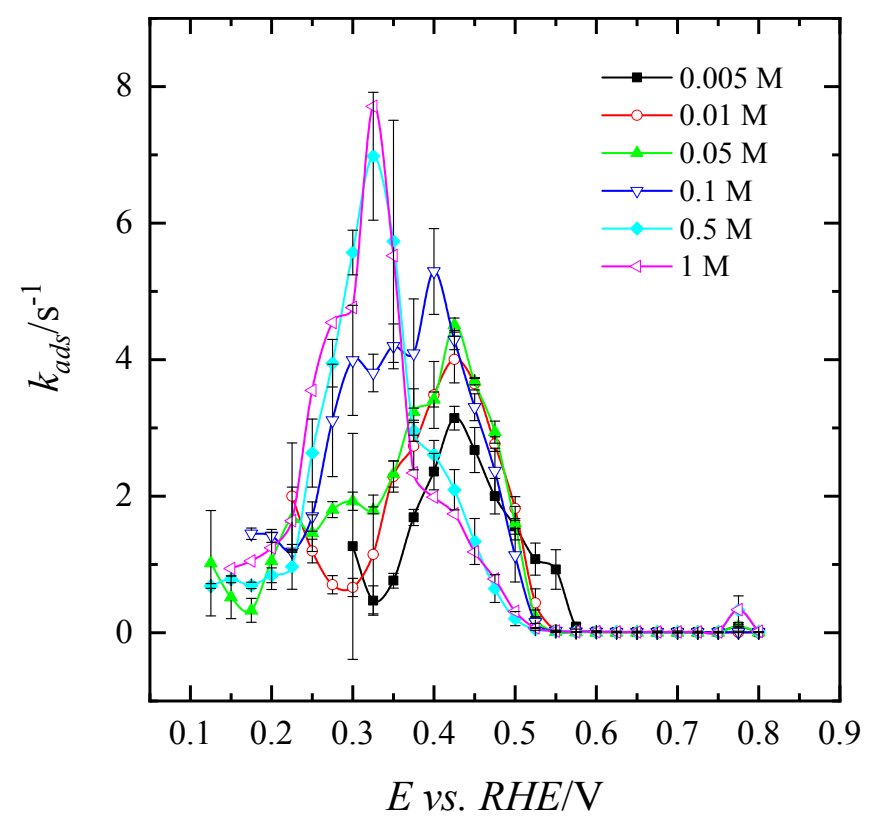

Figure $8 . k_{\text {ads }}$ vs. $E$ measured for the transients recorded during the pulsed voltammetry in $0.1 \mathrm{M} \mathrm{HClO}_{4}$ for different formic acid concentrations. 
Similarly, as also predicted in ${ }^{8}$, if the adsorption of formate follows a Langmuir isotherm, the rate of formation of adsorbed $\mathrm{CO}$ when $\theta_{\mathrm{CO}}=0$, i.e., $k_{\mathrm{ads}}$, at the potential at which it is maximum, $k_{\mathrm{ads}}^{\max }$, must increase with increasing concentration of formic acid according to:

$$
\log k_{\mathrm{ads}}^{\max }=A+(1-\beta) \log c_{\mathrm{HCOOH}}
$$

with $A=\left\{\log \frac{k^{0}}{2}-(1-\beta)\left[\frac{\left(E_{\mathrm{pzc}}-E_{\mathrm{eq}}\right)}{2.3 R T}+\left[\log \beta-\log (1-\beta)-\log \sqrt{K_{\mathrm{L}}}\right]\right]\right\}$. (Please note that there is a typographical error in Eq. 30 of ${ }^{8}$ which has been corrected here.)

A semilogarithmic plot of $E_{\max }$ vs. $C_{\mathrm{HCOOH}}$ is shown on Figure $6 \mathrm{~B}$ (black squares and dashed black line), according to which the potential at which the rate of dehydration of formic acid to yield adsorbed $\mathrm{CO}$ on $\mathrm{Pt}$ is maximum shifts negatively by $49 \mathrm{mV}$ every tenfold increase of the formic acid concentration. This is smaller than the $-59 \mathrm{mV}$ shift predicted by Eq. 10. However, Eq. 10 assumes that the adsorption of formate is Langmuirian, which implies that the maximum corresponds always to the same formate coverage. This does not take into account the possibility of either repulsive or attractive interactions between neighboring adsorbed formate molecules at intermediate to high coverage, and, most importantly, does not take into account the overlap on $\operatorname{Pt}(100)$ 
between hydrogen and formate adsorption. As discussed in the previous section, this overlap affects the formate adsorption isotherm exactly in the potential region where the maximum rate of dehydration happens. The consequence is that a potential more positive than expected in the absence of a competing adsorbate (hydrogen) will be required to achieve the formate coverage corresponding to the maximum rate of dehydration (which, furthermore, will not anymore be the same at all $c_{\mathrm{HCOOH}}$ ), and the shift of $E_{\max }$ with $C_{\mathrm{H} C O O H}$ will be smaller than expected, as indeed observed.

A double logarithmic plot of $k_{\mathrm{ads}}^{\max }$ vs. $\mathrm{CHCOOH}_{\mathrm{H}}$ is also included in Figure 9 (red circles and dashed red line). The slope of the plot, 0.16 is considerably smaller than expected from Eq. 11 if $\beta=0.5$, which is in apparent contradiction with a previous determination of the Tafel slope of Reaction 8 of $128 \mathrm{mV} .^{7}$ However, like Eq. 10, Eq. 11 is only correct if the adsorption of formate is Langmuirian and fails to take into account the competition for the adsorption sites between hydrogen and formate in the potential region where $E_{\max }$ occurs. In particular, whereas a Langmuirian adsorption implies that the formate coverage at $E_{\max }$ will always be the same whatever the concentration of formic acid, the shift of $E_{\max }$ into the hydrogen adsorption region when ${ }_{\mathrm{H}} \mathrm{HCOH}$ increases will result in a 
lower formate coverage at $E_{\max }$ and, therefore, in a dehydration rate lower than expected from Eq. 11, thus explaining a gradient in Figure 6B (red line) smaller than expected.

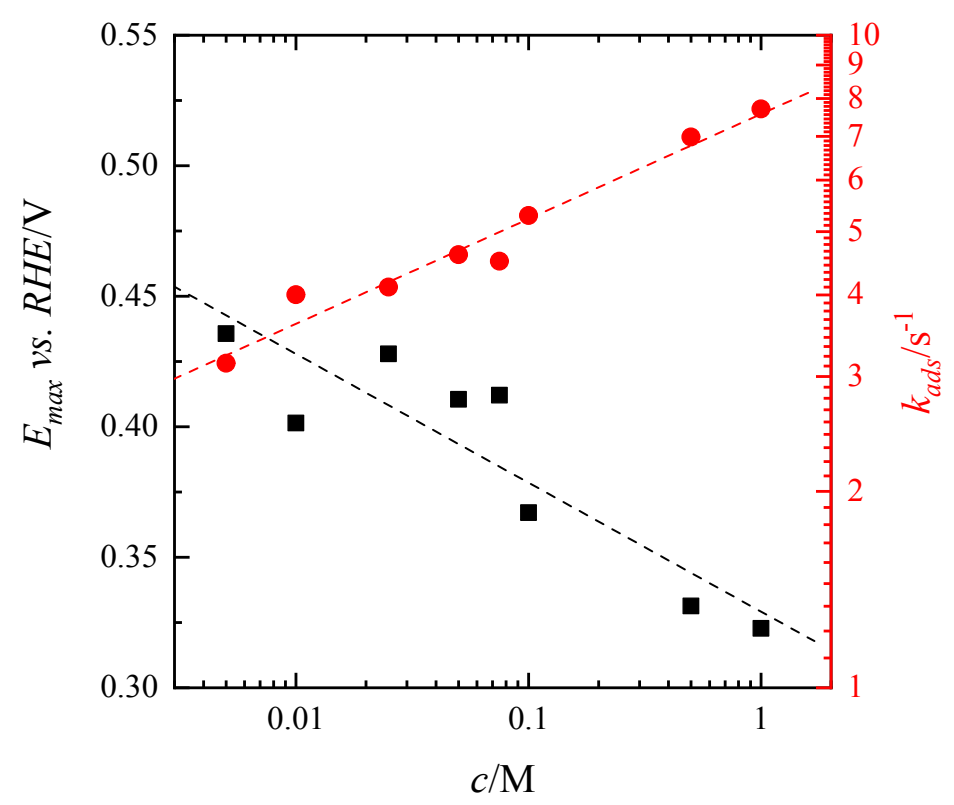

Figure 9. Plot of the potential for the maximum $k_{\text {ads }}$ and it value vs. concentration.

We would like to finish this section by highlighting that the potential dependence of the rate of formation of adsorbed $\mathrm{CO}$ from the dehydration of formic acid (Figure 8) is only consistent with a mechanism in which an oxidative electroadsorption step is followed by a rate-determining reduction step. The only possible alternative to the sequence formate adsorption - formate reduction is the fast adsorption of - $\mathrm{COOH}$ followed by its rate- 
determining reduction, but this would imply the very unlikely fast activation of the $\mathrm{C}-\mathrm{H}$ bond in formic acid. This, together with the reasonable agreement with the predictions made in ${ }^{8}$ of the observed dependence on the concentration of both the potential at which the rate of dehydration is maximum and of the rate at that potential confirm that monodentate adsorbed formate is also the intermediate in the indirect path.

\title{
CONCLUSIONS
}

\author{
A thorough analysis of the dependence of the voltammetric profile of Pt(111) and \\ $\mathrm{Pt}(100)$ electrodes in solutions containing formic acid on the scan rate and on the formic \\ acid concentration, as well as of the current transients in pulsed voltammetry \\ experiments, has allowed us to provide evidence that an adsorbed-formate species is \\ the reactive intermediate both in the direct and the indirect path of the formic acid \\ oxidation reaction. As bidentate adsorbed formate has been shown to be too unreactive, \\ monodentate adsorbed formate must be the reactive species, the last common \\ intermediate in the dual reaction path. After the oxidative electroadsorption of
}


monodentate formate, and depending on the potential, it can either be reduced to yield adsorbed $\mathrm{CO}$ (a catalytic poison) or oxidized to the final product, $\mathrm{CO}_{2}$.

In the direct path, although unreactive, bidentate adsorbed formate is not just an innocent spectator. At low to medium coverages, the presence of neighboring bidentate formate helps stabilize the monodentate reactive species, which might explain the second order of the reaction with respect to bidentate formate reported in previous work. ${ }^{8,28}$ Other adsorbed species, like, e.g., specifically adsorbed sulfate, can also play this role. However, at coverages above $50 \%$ of the maximum, the blocking effect of bidentate formate overcomes its effect on the stabilization of monodentate formate, and increasing its coverage leads to the inactivation of the electrode surface. At very high coverages, a spike in the cyclic voltammograms suggests a disorder-order phase transition within the formate adlayer that leads to a further deactivation of the surface. A similar transition has been found previously on $\mathrm{Au}(111)$ electrodes ${ }^{30}$ but, as far as we know, had never been reported for $\mathrm{Pt}(111)$ before. 
Since the specific adsorption of formate starts around the pzfc, neither the dehydration to adsorbed $\mathrm{CO}$ nor the oxidation to $\mathrm{CO}_{2}$ can occur at a potential more negative than the pzfc. This leads to differences between $\mathrm{Pt}(111)$ and $\mathrm{Pt}(100)$ regarding the increase in the reaction rate along the direct path with increasingly positive potential, as well as regarding their activity for the formation of the catalytic poison. In the case of the Pt(100) surface, the pzfc occurs in a potential region in which the surface is covered by adsorbed hydrogen and prevents the adsorption of formate, whereas in the case of $\mathrm{Pt}(111)$, most of the hydrogen has desorbed at the pzfc. The consequence is that, in the case of Pt(100), formate immediately replaces hydrogen as soon at the latter desorbs, leading to a sharp rise in formate coverage and therefore in the current for the direct oxidation of formic acid. On the contrary, on $\mathrm{Pt}(111)$ both the formate coverage and the current increase gradually with increasing potential.

Regarding the formation of adsorbed $\mathrm{CO}$, due to the more negative pzfc of $\operatorname{Pt}(100)$, a sufficiently high coverage of adsorbed formate can be reached at a relatively negative potential, leading to a high rate of reduction of adsorbed formate and a high rate of $\mathrm{CO}$ 
poisoning. On the contrary, on $\mathrm{Pt}(111)$, a high coverage of adsorbed formate can only be reached at relatively positive potentials, at which the reduction of adsorbed formate to adsorbed $\mathrm{CO}$ is slow, thus explaining the slow poisoning by $\mathrm{CO}$ of $\mathrm{Pt}(111)$ electrodes in the absence of defects. On Pt(100), the dependence of the rate of formation of adsorbed $\mathrm{CO}$ on the potential shows a bell shape. The potential at which the rate of formation is maximum decreases and the rate at the maximum increases with increasing concentration of formic acid, in good agreement with previous predictions in which adsorbed $\mathrm{CO}$ is formed by the adsorption of formate followed by the reduction of adsorbed formate.

The presented results point out that monodentate adsorbed formate is the last common intermediate for both direct and indirect pathways on Pt electrodes, and this conclusion can be extrapolated to other metals. Depending on the energetics of each pathway on the different electrodes, their reaction rates would be different, giving different behaviour. For Pt electrodes, the reaction rates for the intermediate pathway on $\mathrm{Pt}(111)$ are negligible, because a sufficiently high formate coverage happens only at potentials 
too positive for the step leading to the formation of $\mathrm{CO}$ through reduction of the monodentate adsorbed formate to be fast, whereas on $\mathrm{Pt}(100)$ there is a potential window where this reaction is possible at higher formate coverage. Evidence that oxidation of formic acid also proceeds through adsorbed monodentate formate on other metal surfaces has been provided in the case of $\mathrm{Au}^{30-31,40-41}$ and $\mathrm{Pd}^{42}$ electrodes, as well as for several metal surfaces at the solid-gas interface. ${ }^{43-48}$ Cyclic voltammetry and DFT calculations suggested that the stabilization of monodentate adsorbed formate can take place by the presence of adatoms or other adsorbed species on the Pt surface,,$^{21}$ and a similar effect has been proposed recently for Bi-modified Pd nanoparticles also supported by theoretical calculations. ${ }^{49}$ Thus, the mechanism presented here can be considered as general, the differences between different surfaces being due to the ratio between the rate constants for each pathway (as in the case of, e.g., $\mathrm{Pd}$ ) and/or to a lower CO adsorption energy (as in the case of $\mathrm{Au}$ ), both of which will depend on the electronic properties of each specific surface. 


\author{
AUTHOR INFORMATION \\ Corresponding Author \\ E-mail for A.C: angel.cuestaciscar@abdn.ac.uk \\ E-mail for E.H.: herrero@ua.es
}

\title{
Author Contributions
}

The manuscript was written through contributions of all authors. All authors have given approval to the final version of the manuscript.

\author{
Notes \\ The authors declare no competing financial interest.
}

ASSOCIATED CONTENT

Supporting Information. Supporting information containing additional figures are available free of charge. 


\section{ACKNOWLEDGMENT}

This work has been financially supported by MINECO-FEDER (Spain) through project

CTQ2016-76221-P. A.B. and A.C. gratefully acknowledge the support of the University

of Aberdeen.

\section{REFERENCES}

1. Jahn, H., Beiträge zur Elektrochemie und Thermochemie einiger organischer Säuren. Ann. Phys. Chem. 1889, 273, 408-443.

2. $\quad$ Salzer, F., Beitrag Zur Elektrolyse der Ameisensäure und Oxalsäure, sowie des Kaliumkarbonats. Z. Elektrotech. Elektrochem. 1902, 8, 893-903.

3. Müller, E.; Tanaka, S., Über die pulsierende elektrolytische Oxydation der Ameisensäure. Z. Elektrochem. Angew. Phy. Chem. 1928, 34, 256-264.

4. Capon, A.; Parsons, R., The oxidation of formic acid at noble metal electrodes Part III. Intermediates and mechanism on platinum electrodes J. Electroanal. Chem. 1973, 45, 205-231. 5. Beden, B.; Bewick, A.; Lamy, C., A study by electrochemically modulated infrared reflectance spectroscopy of the electrosorption of formic-acid at a platinum-electrode. $J$. Electroanal. Chem. 1983, 148, 147-160.

6. Miki, A.; Ye, S.; Osawa, M., Surface-enhanced IR absorption on platinum nanoparticles: an application to real-time monitoring of electrocatalytic reactions. Chem. Commun. 2002, 15001501.

7. Cuesta, A.; Cabello, G.; Gutierrez, C.; Osawa, M., Adsorbed formate: the key intermediate in the oxidation of formic acid on platinum electrodes. Phys. Chem. Chem. Phys. 2011, 13, 20091-20095.

8. Cuesta, A.; Cabello, G.; Osawa, M.; Gutiérrez, C., Mechanism of the Electrocatalytic Oxidation of Formic Acid on Metals. ACS Catal. 2012, 2, 728-738.

9. $\quad$ Chen, Y. X.; Heinen, M.; Jusys, Z.; Behm, R. J., Bridge-bonded formate: Active intermediate or spectator species in formic acid oxidation on a Pt film electrode? Langmuir 2006, 22, 10399-10408.

10. Xu, J.; Yuan, D. F.; Yang, F.; Mei, D.; Zhang, Z. B.; Chen, Y. X., On the mechanism of the direct pathway for formic acid oxidation at a $\mathrm{Pt}(111)$ electrode. Phys. Chem. Chem. Phys. 2013, 15, 4367-4376. 
11. Wang, H.-F.; Liu, Z.-P., Formic Acid Oxidation at Pt/H2O Interface from Periodic DFT Calculations Integrated with a Continuum Solvation Model. J. Phys. Chem. C 2009, 113, 1750217508 .

12. Chen, Y. X.; Heinen, M.; Jusys, Z.; Behm, R. J., Kinetics and mechanism of the electrooxidation of formic acid - Spectroelectrochemical studies in a flow cell. Angew. Chem. Int. Ed. 2006, 45, 981-985.

13. Jiang, K.; Zhang, H. X.; Zou, S.; Cai, W. B., Electrocatalysis of formic acid on palladium and platinum surfaces: From fundamental mechanisms to fuel cell applications. Phys. Chem. Chem. Phys. 2014, 16, 20360-20376.

14. Okamoto, H.; Numata, Y.; Gojuki, T.; Mukouyama, Y., Different behavior of adsorbed bridge-bonded formate from that of current in the oxidation of formic acid on platinum.

Electrochim. Acta 2014, 116, 263-270.

15. Neurock, M.; Janik, M.; Wieckowski, A., A first principles comparison of the mechanism and site requirements for the electrocatalytic oxidation of methanol and formic acid over Pt. Faraday Discuss. 2009, 140, 363-378.

16. Mei, D.; He, Z.-D.; Jiang, D. C.; Cai, J.; Chen, Y.-X., Modeling of Potential Oscillation during Galvanostatic Electrooxidation of Formic Acid at Platinum Electrode. J. Phys. Chem. C 2014, 118, 6335-6343.

17. Joo, J.; Uchida, T.; Cuesta, A.; Koper, M. T. M.; Osawa, M., Importance of Acid-Base Equilibrium in Electrocatalytic Oxidation of Formic Acid on Platinum. J. Am. Chem. Soc. 2013, 135, 9991-9994.

18. Joo, J.; Uchida, T.; Cuesta, A.; Koper, M. T. M.; Osawa, M., The effect of $\mathrm{pH}$ on the electrocatalytic oxidation of formic acid/formate on platinum: A mechanistic study by surfaceenhanced infrared spectroscopy coupled with cyclic voltammetry. Electrochim. Acta 2014, 129, 127-136.

19. Brimaud, S.; Solla-Gullon, J.; Weber, I.; Feliu, J. M.; Behm, R. J., Formic Acid Electrooxidation on Noble-Metal Electrodes: Role and Mechanistic Implications of $\mathrm{pH}$, Surface Structure, and Anion Adsorption. ChemElectroChem 2014, 1, 1075-1083.

20. Perales-Rondón, J. V.; Brimaud, S.; Solla-Gullón, J.; Herrero, E.; Behm, R. J.; Feliu, J. M., Further Insights into the Formic Acid Oxidation Mechanism on Platinum: $\mathrm{pH}$ and Anion Adsorption Effects. Electrochim. Acta 2015, 180, 479-485.

21. Ferre-Vilaplana, A.; Perales-Rondón, J. V.; Busó-Rogero, C.; Feliu, J. M.; Herrero, E., Formic acid oxidation on platinum electrodes: a detailed mechanism supported by experiments and calculations on well-defined surfaces. J. Mater. Chem. A 2017, 5, 21773-21784.

22. Perales-Rondon, J. V.; Herrero, E.; Feliu, J. M., Effects of the anion adsorption and pH on the formic acid oxidation reaction on Pt(111) electrodes. Electrochim. Acta 2014, 140, 511517.

23. Cuesta, A., Formic acid oxidation on metal electrodes, in Encyclopedia of Interfacial Chemistry: Surface Science and Electrochemistry, Vol. 5, Wandelt, K. (Ed.), Elsevier: 2018; pp 620-632.

24. Herrero, E.; Feliu, J. M., Understanding formic acid oxidation mechanism on platinum single crystal electrodes. Curr. Opin. Electrochem. 2018, 9, 145-150.

25. Clavilier, J.; Armand, D.; Sun, S. G.; Petit, M., Electrochemical adsorption behaviour of platinum stepped surfaces in sulphuric acid solutions J. Electroanal. Chem. 1986, 205, 267-277. 
26. Herrero, E.; Orts, J. M.; Aldaz, A.; Feliu, J. M., Scanning tunneling microscopy and electrochemical study of the surface structure of $\operatorname{Pt}(10,10,9)$ and $\operatorname{Pt}(11,10,10)$ electrodes prepared under different cooling conditions. Surf. Sci. 1999, 440, 259-270.

27. Grozovski, V.; Climent, V.; Herrero, E.; Feliu, J. M., Intrinsic activity and poisoning rate for $\mathrm{HCOOH}$ oxidation on platinum stepped surfaces. Phys. Chem. Chem. Phys. 2010, 12, 88228831.

28. Grozovski, V.; Climent, V.; Herrero, E.; Feliu, J. M., Intrinsic Activity and Poisoning Rate for HCOOH Oxidation at Pt(100) and Vicinal Surfaces Containing Monoatomic (111) Steps. ChemPhysChem 2009, 10, 1922-1926.

29. Grozovski, V.; Vidal-Iglesias, F. J.; Herrero, E.; Feliu, J. M., Adsorption of Formate and Its Role as Intermediate in Formic Acid Oxidation on Platinum Electrodes. ChemPhysChem 2011, 12, 1641-1644.

30. Kibler, L. A.; Al-Shakran, M., Adsorption of Formate on $\mathrm{Au}(111)$ in Acid Solution: Relevance for Electro-Oxidation of Formic Acid. J. Phys. Chem. C 2016, 120, 16238-16245. 31. Abdelrahman, A.; Hermann, J. M.; Jacob, T.; Kibler, L. A., Adsorption of Acetate on $\mathrm{Au}(111)$ : An in-situ Scanning Tunnelling Microscopy Study and Implications on Formic Acid Electrooxidation. ChemPhysChem 2019.

32. Busó-Rogero, C.; Ferre-Vilaplana, A.; Herrero, E.; Feliu, J. M., The role of formic acid/formate equilibria in the oxidation of formic acid on Pt (111). Electrochem. Commun. 2019, 98, 10-14.

33. Domke, K.; Herrero, E.; Rodes, A.; Feliu, J. M., Determination of the potentials of zero total charge of $\operatorname{Pt}(100)$ stepped surfaces in the $01(-1)$ zone. Effect of the step density and anion adsorption. J. Electroanal. Chem. 2003, 552, 115-128.

34. Garcia-Araez, N.; Climent, V.; Herrero, E.; Feliu, J. M.; Lipkowski, J., Thermodynamic approach to the double layer capacity of a $\mathrm{Pt}(111)$ electrode in perchloric acid solutions. Electrochim. Acta 2006, 51, 3787-3793.

35. Rizo, R.; Sitta, E.; Herrero, E.; Climent, V.; Feliu, J. M., Towards the understanding of the interfacial $\mathrm{pH}$ scale at $\mathrm{Pt}(111)$ electrodes. Electrochim. Acta 2015, 162, 138-145.

36. Nieuwenhuys, B. E.; Sachtler, W. M. H., Crystal face specificity of nitrogen adsorption on a platium field emission tip. Surf. Sci. 1973, 34, 317-336.

37. Clavilier, J., Pulsed linear sweep voltammetry with pulses of constant level in a potential scale, a polarization demanding condition in the study of platinum single-crystal electrodes. $J$. Electroanal. Chem. 1987, 236, 87-94.

38. Cuesta, A., Atomic Ensemble Effects in Electrocatalysis: The Site-Knockout Strategy. ChemPhysChem 2011, 12, 2375-2385.

39. Leiva, E.; Iwasita, T.; Herrero, E.; Feliu, J. M., Effect of adatoms in the electrocatalysis of $\mathrm{HCOOH}$ oxidation. A theoretical model. Langmuir 1997, 13, 6287-6293.

40. Cuesta, A.; Cabello, G.; Hartl, F. W.; Escudero-Escribano, M.; Vaz-Domínguez, C.; Kibler, L. A.; Osawa, M.; Gutiérrez, C., Electrooxidation of formic acid on gold: An ATRSEIRAS study of the role of adsorbed formate. Catal. Today 2013, 202, 79-86.

41. Abdelrahman, A.; Hermann, J. M.; Kibler, L. A., Electrocatalytic Oxidation of Formate and Formic Acid on Platinum and Gold: Study of $\mathrm{pH}$ Dependence with Phosphate Buffers. Electrocatalysis 2017, 8, 509-517.

42. Miyake, H.; Okada, T.; Samjeské, G.; Osawa, M., Formic acid electrooxidation on Pd in acidic solutions studied by surface-enhanced infrared absorption spectroscopy. Phys. Chem. Chem. Phys. 2008, 10, 3662-3669. 
43. Marcinkowski, M. D.; Murphy, C. J.; Liriano, M. L.; Wasio, N. A.; Lucci, F. R.; Sykes, E. C. H., Microscopic View of the Active Sites for Selective Dehydrogenation of Formic Acid on $\mathrm{Cu}(111)$. ACS Catal. 2015, 5, 7371-7378.

44. Ying, D. H. S.; Robert, J. M., Thermal desorption study of formic acid decomposition on a clean $\mathrm{Cu}(110)$ surface. J. Catal. 1980, 61, 48-56.

45. Yoo, J. S.; Abild-Pedersen, F.; Nørskov, J. K.; Studt, F., Theoretical Analysis of Transition-Metal Catalysts for Formic Acid Decomposition. ACS Catal. 2014, 4, 1226-1233. 46. Bowker, M.; Madix, R. J., XPS, UPS and thermal desorption studies of the reactions of formaldehyde and formic acid with the $\mathrm{Cu}(110)$ surface. Surf. Sci. 1981, 102, 542-565.

47. Hayden, B. E.; Prince, K.; Woodruff, D. P.; Bradshaw, A. M., An iras study of formic acid and surface formate adsorbed on $\mathrm{Cu}(110)$. Surf. Sci. 1983, 133, 589-604.

48. $\quad$ Baber, A. E.; Mudiyanselage, K.; Senanayake, S. D.; Beatriz-Vidal, A.; Luck, K. A.; Sykes, E. C. H.; Liu, P.; Rodriguez, J. A.; Stacchiola, D. J., Assisted deprotonation of formic acid on $\mathrm{Cu}(111)$ and self-assembly of $1 \mathrm{D}$ chains. Phys. Chem. Chem. Phys. 2013, 15, 1229112298 .

49. Qin, X.; Li, H.; Xie, S.; Li, K.; Jiang, T.; Ma, X.-Y.; Jiang, K.; Zhang, Q.; Terasaki, O.; Wu, Z.; Cai, W.-B., Mechanistic Analysis-Guided Pd-based Catalysts for Efficient Hydrogen Production from Formic Acid Dehydrogenation. ACS Catal. 2020, 10, 3921-3932. 


\section{TOC}

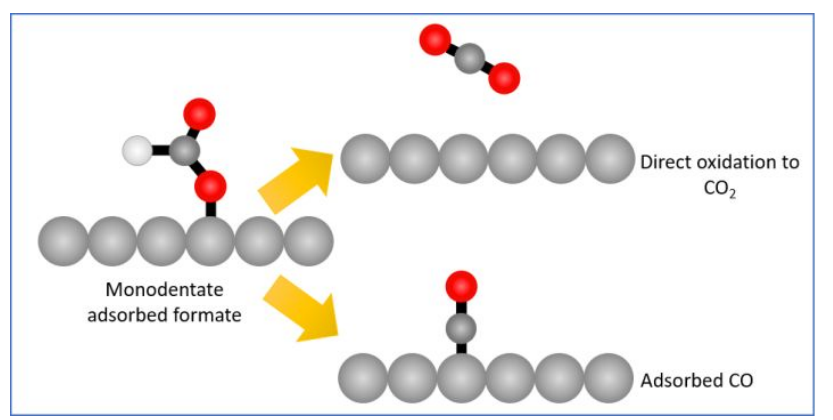


